
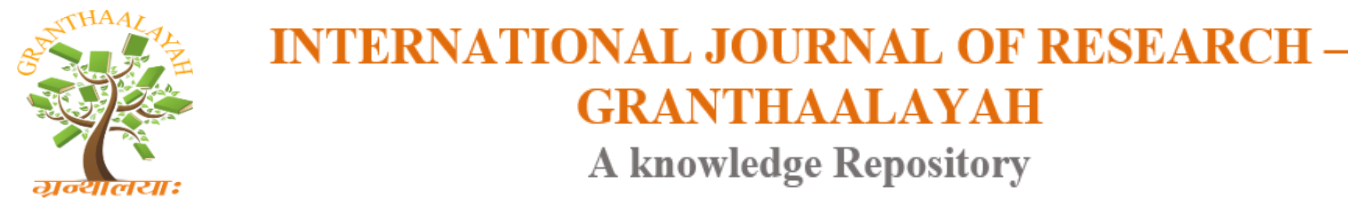

Science

\title{
INTRAVENOUS APPLICATION OF HELIXOR® IN GYNECOLOGICAL ONCOLOGY: IS IT SAFE?
}

\author{
Yong-II Ji ${ }^{* 1}$ \\ ${ }^{* 1}$ Department of Obstetrics and Gynecology, Inje University, Haeundae Paik Hospital, Busan, \\ South Korea
}

\begin{abstract}
Background: Traditional mistletoe (Viscum album L.) therapy has been frequently used in patients with cancer in Europe. The different mistletoe formulations available for oncological use

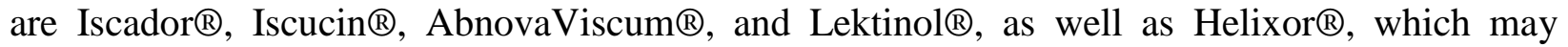
improve therapeutic outcomes following intravenous (i.v.) administration and therefore, is becoming more commonly used.

Method: I conducted an observational study in four different University Hospital Centers and the frequency of adverse drug reactions (ADRs) induced by the i.v. infusion of Helixor® was determined.

Result: of the 108 patients with gynecological cancer who received i.v. infusions of Helixor ${ }^{\circledR}$, $10(9.3 \%)$ reported mild ADRs, and no serious ADRs were reported.

Conclusion: Therefore, i.v. infusion of Helixor ${ }^{\circledR}$ was determined to be safe, and prospective efficacy studies are recommended.

Keywords: Intravenous Infusion of Helixor ${ }^{\circledR}$; Mistletoe; Gynecological Cancer.

Cite This Article: Yong-Il Ji. (2017). "INTRAVENOUS APPLICATION OF HELIXOR® IN GYNECOLOGICAL ONCOLOGY: IS IT SAFE?." International Journal of Research - Granthaalayah, 5(10), 307-312. https://doi.org/10.29121/granthaalayah.v5.110.2017.2306.
\end{abstract}

\section{Introduction}

Mistletoe (Viscum album L.), a plant with a partially woody stem, is a semi-parasite that lives epiphytically on the branches of a variety of deciduous and coniferous trees [1]. The stems and leaves of mistletoe are used as herbal drugs, and various commercially available preparations are formulated from the crude mistletoe plant material [1]. Mistletoe extracts are complex multicomponent herbal preparations that contain various biologically active substances such as mistletoe lectins (ML), viscotoxins, amino acids, flavonoids, phenylpropanoids, triterpenes, phytosterol, alkaloids, polyalcohols, and polysaccharides, the content of which may vary depending on harvest time, species of the host tree, and manufacturing process [2] [3]. The different fractions and components exhibit varying activities including cytotoxic, antineoplastic, and immunomodulatory, which appear to be dose-dependent [4]. 
Mistletoe extracts are the most frequently prescribed complementary therapies for patients with cancer in Europe, especially in Germany, Switzerland, and Austria [5]. Mistletoe preparations such as AbnobaVISCUM ${ }^{\circledR}$, Helixor $^{\circledR}$, Iscador ${ }^{\circledR}$, and Iscucin $^{\circledR}$ are most commonly administered as subcutaneous (s.c.) injections starting at a low dose, which is gradually increased over time based on individual patient responses [5]. Increasingly, mistletoe preparations are also administered at high initial doses as s.c. injections, intravenous (i.v.) infusions, or intratumorally (i.t.), depending on the location of the tumor, disease stage, and the experience of the physician [6]. There appears to be accumulating evidence of the safety, improvement of the quality of life (QOL), and reduction in adverse drug reactions (ADRs) to conventional therapies, associated with traditional s.c. mistletoe therapy [5].

To date, no widely accepted treatment scheme is available for mistletoe preparations, although s.c. injections of the different preparations twice a week are frequently used [1]. The PubMed database alone lists more than 1,200 citations for "mistletoe" with approximately 50 new entries each year [6]. A multitude of laboratory-based studies demonstrated immune stimulation, cytotoxicity, proapoptotic effects, antiangiogenesis, and DNA stabilization while animal experiments have found tumor-reducing effects [7].

In recent years, the number and quality of clinical research studies on mistletoe therapy reporting improved patient outcomes have increased, including studies of its coadministration with chemotherapeutic agents to reduce adverse effects and improve the QOL of patients with breast, ovarian, and lung cancers [8].

Mistletoe extracts have shown a wide range of immunological effects including increased macrophage activity, proliferation of neutrophils, enhanced C-reactive protein levels, cytotoxic complement activation, and NK-cell cytotoxicity by inducing CD3+CD4+ $\mathrm{T}$ cells to release interferon (IFN)- $\gamma[9][10]$.

Helixor® is the pure, sterile-filtered, aqueous fresh extract of the plant $V$. album L. (whiteberried mistletoe). Standardized production processes as well as continuous physical, chemical, and biological quality control, including the assessment of cytotoxic effects on MOLT 4 leukemia cells to determine the biological activity of the mistletoe product, guarantee a consistent batch-to-batch quality. The most recent, high-quality studies have provided evidence of improved QOL and tolerability of chemotherapy during concomitant supportive therapy with Helixor ${ }^{\circledR}$ products. Furthermore, a recent study showed that there are no indications that these effects exert a negative influence on conventional standard oncological therapy.

This study investigated potential adverse drug reactions (ADRs) of Helixor® administered to patients with cancer who visited four different hospitals during the period from March 2014 to August 2015.

\section{Materials and Methods}

A multicenter, observational study was carried out in which Helixor ${ }^{\circledR}$ was coadministered to patients who had been treated for gynecological cancer at four different hospitals from March 
2014 to August 2015 and subsequently came to our hospital for radiology therapy or postsurgery anticancer treatment.

The administration frequency, duration of therapy, and ADRs were investigated for all 108 patients administered Helixor ${ }^{\circledR}$ i.v. The numbers of ADRs experienced per person were determined while their management and outcome were summarized. To identify the potential risks of experiencing an ADR, the doses and preparations that induced ADRs were considered in relation to those the patients were exposed to.

\section{Results}

A total of 108 patients with gynecological cancers who received i.v. Helixor ${ }^{\circledR}$ injections were examined.

As shown in Table 1, ovarian cancer was dominant, and one patient had vaginal cancer. The analysis of the treatment frequency showed that Helixor ${ }^{\circledR}$ was administered once a week, starting with an initial dose of $100 \mathrm{mg}$, and the majority of patients (74) received it more than 20 times (Table 1). Helixor ${ }^{\circledR}$ doses ranged from 100 to $900 \mathrm{mg}$ with a median of $500 \mathrm{mg}$ (Figure 1). Furthermore, most of the patients (73) used Helix or ${ }^{\circledR}$ for over 1 month and less than 6 months while 23 patients used it for more than 6 months (Table 2). In general, Helixor ${ }^{\circledR}$ was administered during chemotherapy (Table 2, n=73), and 18 patients used other forms of treatment during the cancer therapy. ADRs were hardly detected, although occasional allergic or systemic urticarial reactions occurred at the injection sites, and headaches, as well as an increase in liver function tests, were observed (Table 3).

Table 1: Patient cancer types

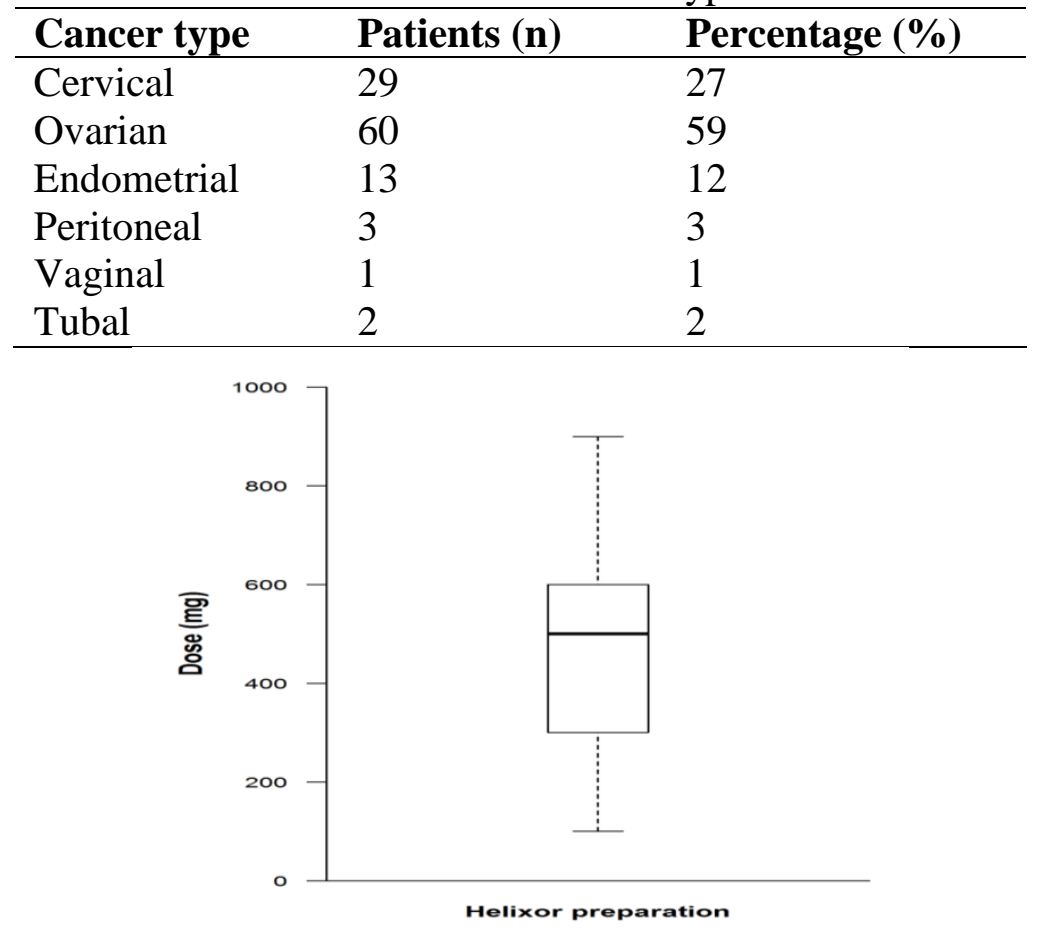

Figure 1: Intravenous (i.v.) Helixor $\left.{ }^{(}\right)$doses 
Table 2: Characteristics of intravenous (i.v.) Helixor ${ }^{\circledR}$ therapy

\section{Characteristics}

Application frequency

$<10$ applications

10-15 applications

16-20 applications

$>20$ applications

Duration of therapy

$<1$ month

1-6 month

$>6$ month

Combined therapy

Chemotherapy

Radiation therapy

Chemotherapy plus Radiation therapy

Others*
25

6

3

74

73

23

73

0

17

18

\section{Patients (n)}

*Including immunotherapy, bisphosphonate, signal transduction inhibitors, and hormonal therapy.

Table 3: Adverse drug reactions (ADRs) attributable to intravenous (i.v.)

\begin{tabular}{|c|c|c|c|}
\hline Affected system/organ & Preferred term & Total patients (n) & Incidence (\%) \\
\hline \multirow[t]{3}{*}{ Gastrointestinal } & Nausea/vomiting & 0 & 0 \\
\hline & Elevated liver function test & 2 & 2 \\
\hline & Generalized edema & 1 & 1 \\
\hline \multirow{3}{*}{$\begin{array}{l}\text { Skin and subcutaneous } \\
\text { tissues }\end{array}$} & Injection site allergy & 1 & 1 \\
\hline & Systemic urticaria & 2 & 2 \\
\hline & Hypersensitivity & 0 & 0 \\
\hline \multirow[t]{4}{*}{ Others } & Headache & 3 & 3 \\
\hline & Myalgia & 0 & 0 \\
\hline & Fatigue & 0 & 0 \\
\hline & Dizziness & 1 & 1 \\
\hline
\end{tabular}




\section{Discussion}

The importance of integrative medicine in oncological care is increasing based on the growth of the evidence supporting its use [6]. In central Europe, white-berried mistletoe (V. album) preparations are not only are one of the most common types of treatments used in integrative medicine, but it is also one of the most commonly prescribed cancer treatments in Germany [6]. By 2017, mistletoe preparations will have been used in the treatment of patients with cancer for 100 years. Mistletoe is a historical folk remedy, and the Dutch physician Ita Wegman was the first to use it in the field of oncology as a mistletoe extract for the treatment of a patient with breast cancer following a recommendation by Rudolf Steiner [6]. The constituents of the mistletoe berry include lectins, viscotoxins, glycoproteins, oligo- and polysaccharides, and membrane lipids [6]. Recent evidence of the potent anti-inflammatory effect of $V$. album via selective inhibition of cyclooxygenase (COX-2) protein expression provides a further rationale for an antitumor role of mistletoe considering the close relationship between cancer and inflammation [11]. Recently, there has been an increase in the number and quality of clinical research studies on mistletoe therapy reporting improved patient outcomes.

After several years of clinical testing, Helixor® products were registered in Germany in 1976 according to German drug legislation (Arzneimittelgesetz, AMG), followed by marketing authorization in February 1982. Thus, it was the first mistletoe product authorized for subcutaneous injection in Germany. Currently, Helixor® mistletoe products have been authorized or registered in Austria, Switzerland, Luxembourg, Sweden, Finland, Latvia, Lithuania, Korea, China, Russia, Chile, Peru, and Canada. The efficacy and safety of Helixor® was reported in 24 clinical studies and numerous case reports, included in a positive monograph published by the Commission C of the German Department of Public Health. Furthermore, there is increasing evidence supporting the safety, improvement of QOL, and reduction of adverse drug reactions (ADRs) to conventional therapies, associated with traditional s.c. mistletoe therapy [5]. However, it has been suggested that high-dose i.v. mistletoe infusions might be even more effective and reduce the risk of tumor metastasis or recurrence, possibly by modulating the immune system and antiangiogenesis effects [5]. In this study, the Helixor ${ }^{\circledR}$ treatment was administered i.v, and no specific concerns were observed other than mild ADRs. Finally, the collective results of this study suggest that Helixor® therapy is safe and effective for use as an adjuvant therapy in patients with gynecological cancers.

\section{Acknowledgment}

This work was supported in part by the Inje University Research Fund.

\section{References}

[1] Melzer J, Iten F, Hostanska K, Saller R: Efficacy and safety of mistletoe preparations (Viscum album) for patients with cancer diseases. A systematic review. Forschende Komplementarmedizin 2009, 16(4):217-226.

[2] Hajto T, Hostanska K, Saller R: Mistletoe therapy from the pharmacologic perspective. Forsch Komplementarmed 1999, 6(4):186-194.

[3] Mansky PJ: Mistletoe and cancer: controversies and perspectives. Seminars in Oncology 2002, 29(6):589-594. 
[4] Hajto T, Hostanska K, Berki T, Palinkas L, Boldizsar F, Nemeth P: Oncopharmacological perspectives of a plant lectin (Viscum album Agglutinin-I): overview of recent results from in vitro experiments and in vivo animal models, and their possible relevance for clinical applications. Evidence-Based Complementary and Alternative Medicine: eCAM 2005, 2(1):5967.

[5] Steele ML, Axtner J, Happe A, Kroz M, Matthes H, Schad F: Safety of intravenous application of mistletoe (Viscum album L.) preparations in oncology: an observational study. Evidence-Based Complementary and Alternative Medicine: eCAM 2014, 2014:236310.

[6] Kroz M, Kienle GS, Feder G, Kaveri S, Rosenzweig S: Mistletoe: from basic research to clinical outcomes in cancer and other indications. Evidence-Based Complementary and Alternative Medicine: eCAM 2014, 2014:987527.

[7] Rostock M, Huber R, Greiner T, Fritz P, Scheer R, Schueler J, Fiebig HH: Anticancer activity of a lectin-rich mistletoe extract injected intratumorally into human pancreatic cancer xenografts. Anticancer Research 2005, 25(3B):1969-1975.

[8] Piao BK, Wang YX, Xie GR, Mansmann U, Matthes H, Beuth J, Lin HS: Impact of complementary mistletoe extract treatment on quality of life in breast, ovarian and non-small cell lung cancer patients. A prospective randomized controlled clinical trial. Anticancer Research 2004, 24(1):303-309.

[9] Jeung IC, Chung YJ, Chae B, Kang SY, Song JY, Jo HH, Lew YO, Kim JH, Kim MR: Effect of helixor A on natural killer cell activity in endometriosis. International Journal of Medical Sciences 2015, 12(1):42-47.

[10] Kuttan G, Kuttan R: Immunological mechanism of action of the tumor reducing peptide from mistletoe extracts (NSC 635089) cellular proliferation. Cancer Letters 1992, 66(2):123-130.

[11] Hegde P, Maddur MS, Friboulet A, Bayry J, Kaveri SV: Viscum album exerts anti-inflammatory effect by selectively inhibiting cytokine-induced expression of cyclooxygenase-2. PloS One 2011, 6(10):e26312.

\footnotetext{
*Corresponding author.

E-mail address: jyimdog@ paik.ac.kr
} 